\title{
ORFEUS Services and Activities to Promote Observational \\ Seismology in Europe and beyond
}

\section{Conference Poster}

\section{Author(s):}

Cauzzi, Carlo Virgilio (iD; Bieńkowski, Jarek; Custódio, Susana; D'Amico, Sebastiano; Evangelidis, Christos; Guéguen, Philippe; Haberland, Christian; Haslinger, Florian (D); Lanzano, Giovanni; Ottemöller, Lars; Rondenay, Stéphane; Sleeman, Reinoud; Strollo, Angelo

\section{Publication date:}

2021

\section{Permanent link:}

https://doi.org/10.3929/ethz-b-000530018

\section{Rights / license:}

In Copyright - Non-Commercial Use Permitted

\section{Originally published in:}

EGU21-6119, https://doi.org/10.5194/egusphere-egu21-6119 
ORFEUS Services and Activities to Promote Observational Seismology in Europe and beyond (EGU21-6119)

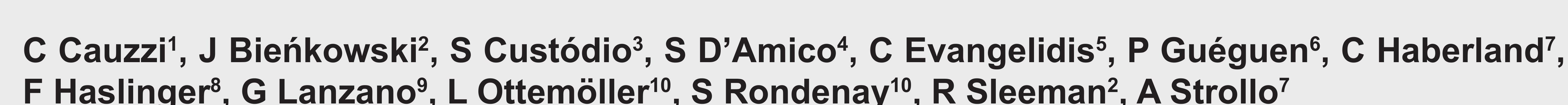

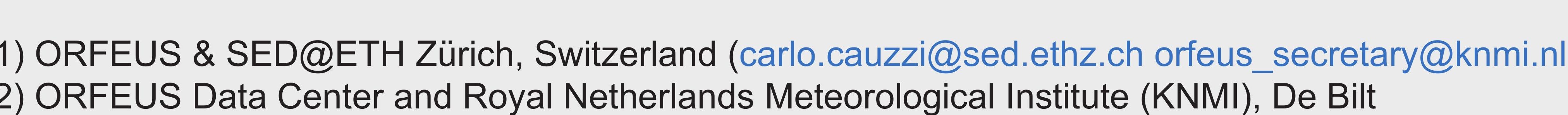

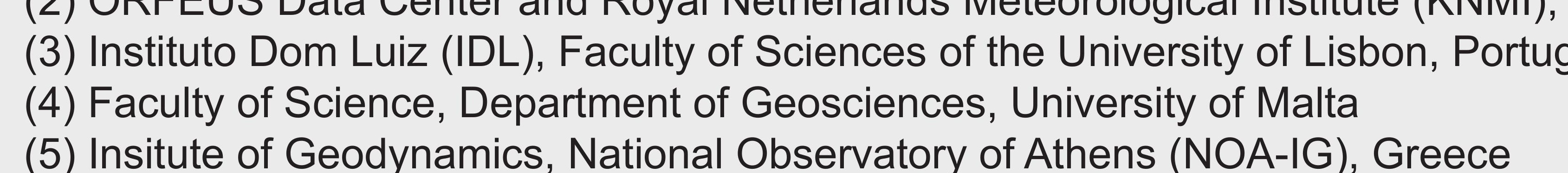

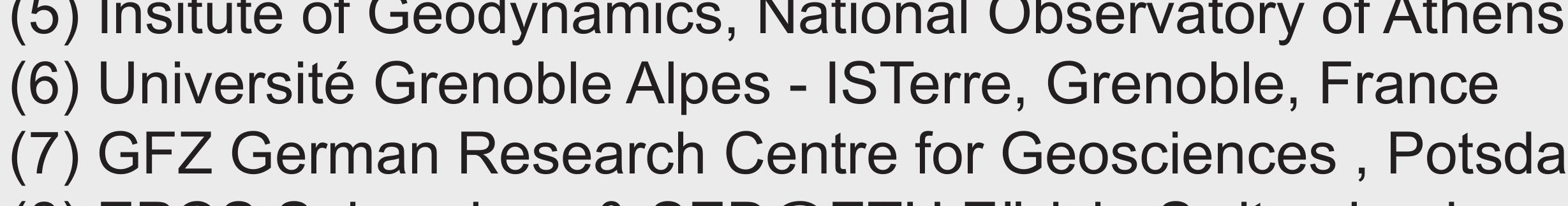

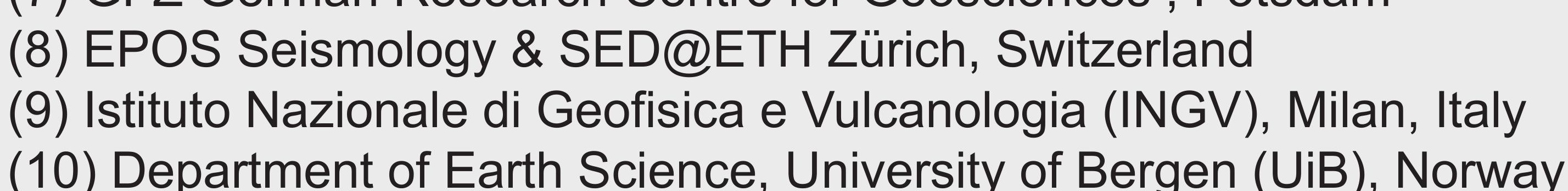

EGGU General

ORFEUS (Observatories and Reasearch Facilities for EUropean Seismology) promotes seismology in Europe through the collection, archival and
waveform data, metadata and associated services and products.

ORFEUS is the waveforms domain in EPOS SEISMOLOGY

$>$ http://orfeus-eu.org

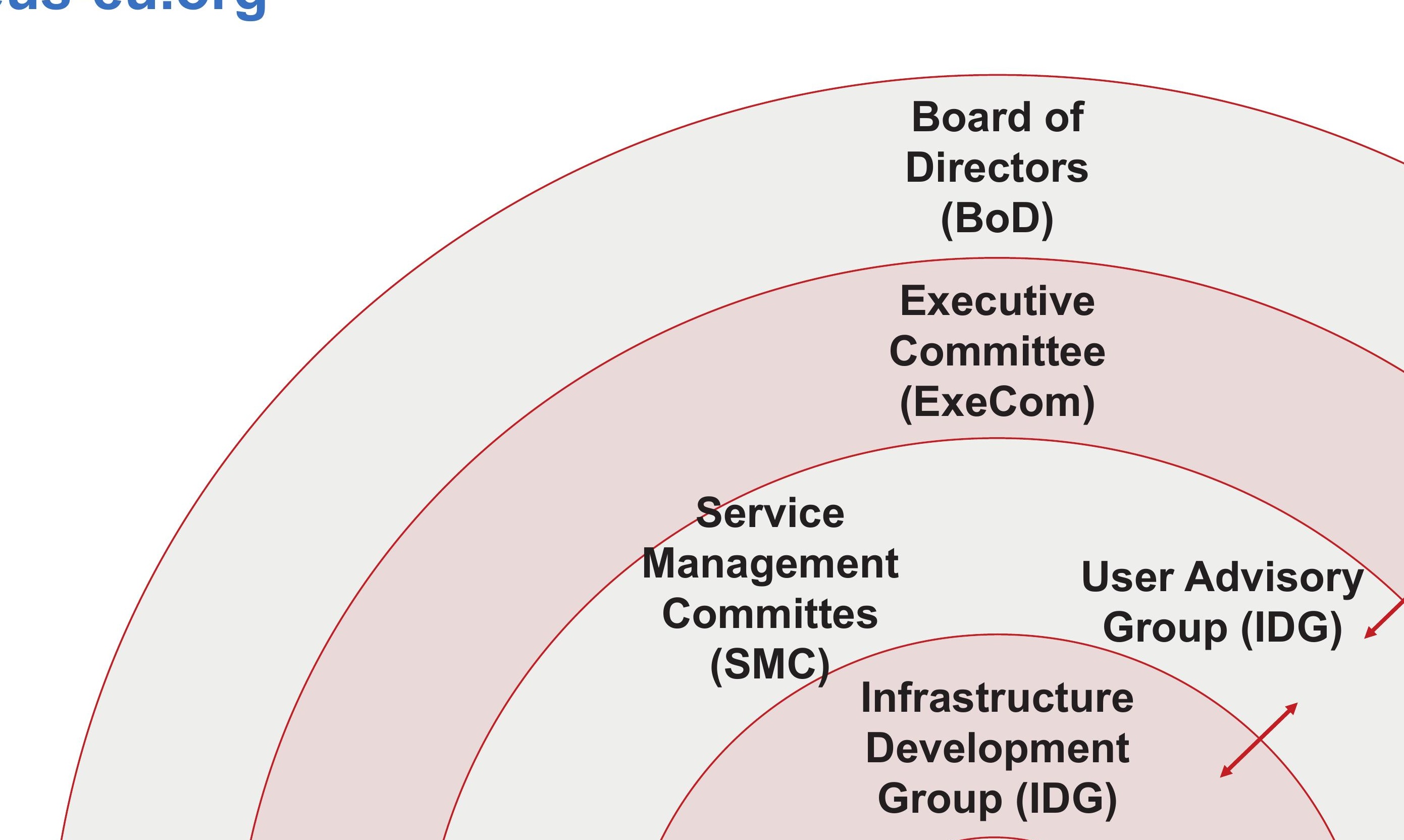

Decision
layer Execution advice

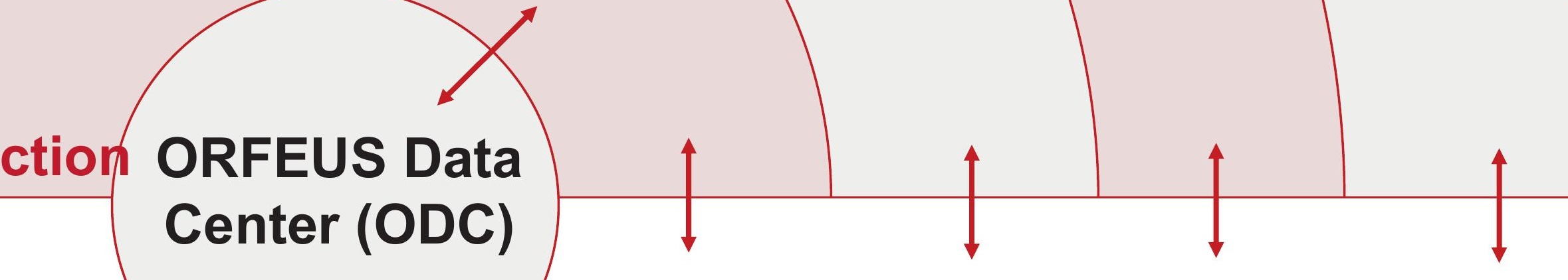

General cordination and
management Secretary General

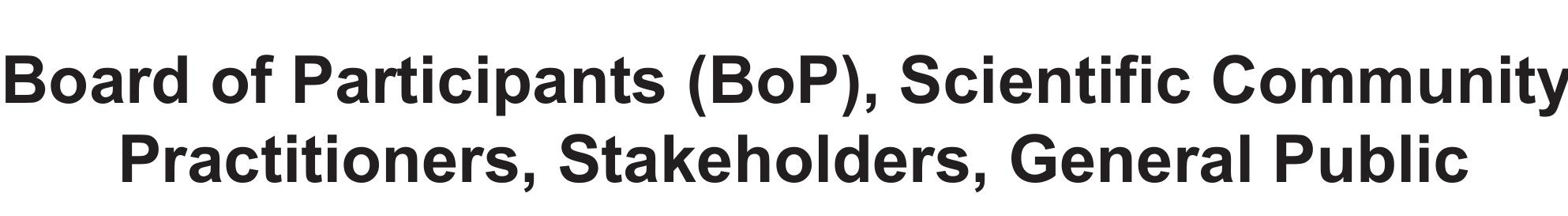

$>$ Existing SMCs: EIDA \& Strong-Motion;

being established: Mobile Pools including OBS (\& Services for Computational Seismology)

(C) EOsc-hub ORFEUS \& Big Data ${ }^{\text {RISE }}$ SERA
Data archival \& dissemination by seismological Activities: of emerging solutions, e.g.:
of implementation massive datasets, e.g.

- very dense $\left(\sim 0^{3}\right)$ arrays of seismic instrumentation;
-fibre-optic and DAS (like $\sim 10^{6}$ seismic
instruments operatic

instruments operating at high sps).

- alternative data formats, e.g., ASDF / HDF5 / Main issues:

$>$ (meta)data quality; - dedicated data processing engines like
Apache Spark; Apache Spark;
- HPC \& cloud solutions, e.g., OpenStack, IBM
Cloud; Amazon Cloud.

$>$ New logging system to provide reliable KPIs
and to measure the load on the EIDA system. $>$ Workflows to improve (meta) data quality including $\mathrm{QC}$ metrics and tools.
$>$ New automated system to transpo information from the data contributors.

$>$ > scalability;

$>$ Focus on users
workshops).

ORFEUS and its associated data centers

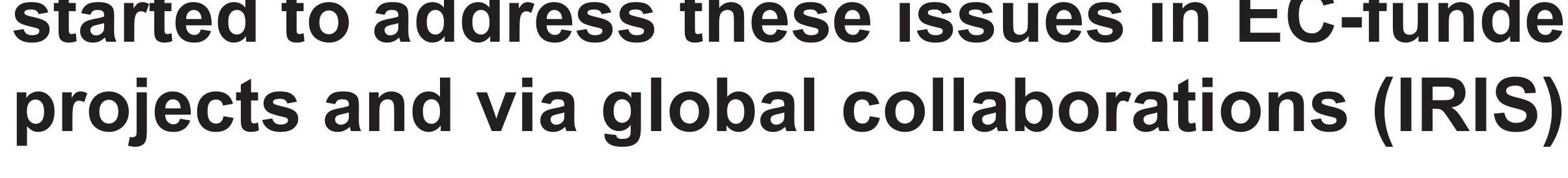

Quinteros J et al. (2021). Exploring Approaches for Large Data in Seismology: User and Data Repository Perspectives, Selsmol. Res. Lett., doi: 10.1

\section{RFEUS Community Services}

Conference sessions (e.g., https://meetingorganizer.copernicus.org/EGU21/session//39308)
Journal special issues (e.g. SRL Focus Section on European Seismic Networks and Associated Services and Products)

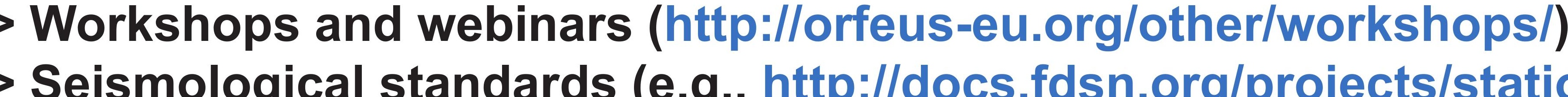

Sotware and travel grants
Joint activities with other international organisaitons (e.g. IRIS DMC, CosmoS)

Always use seismic network DOls in your publications: http://fdsn.org/networks/citation/ \& http://orfeus-eu.org/data/eida/networks/

\section{SERA
the European Integrated Waveform Data Archive}

II and Associated Services (orfeus-eu.org/data/eida)

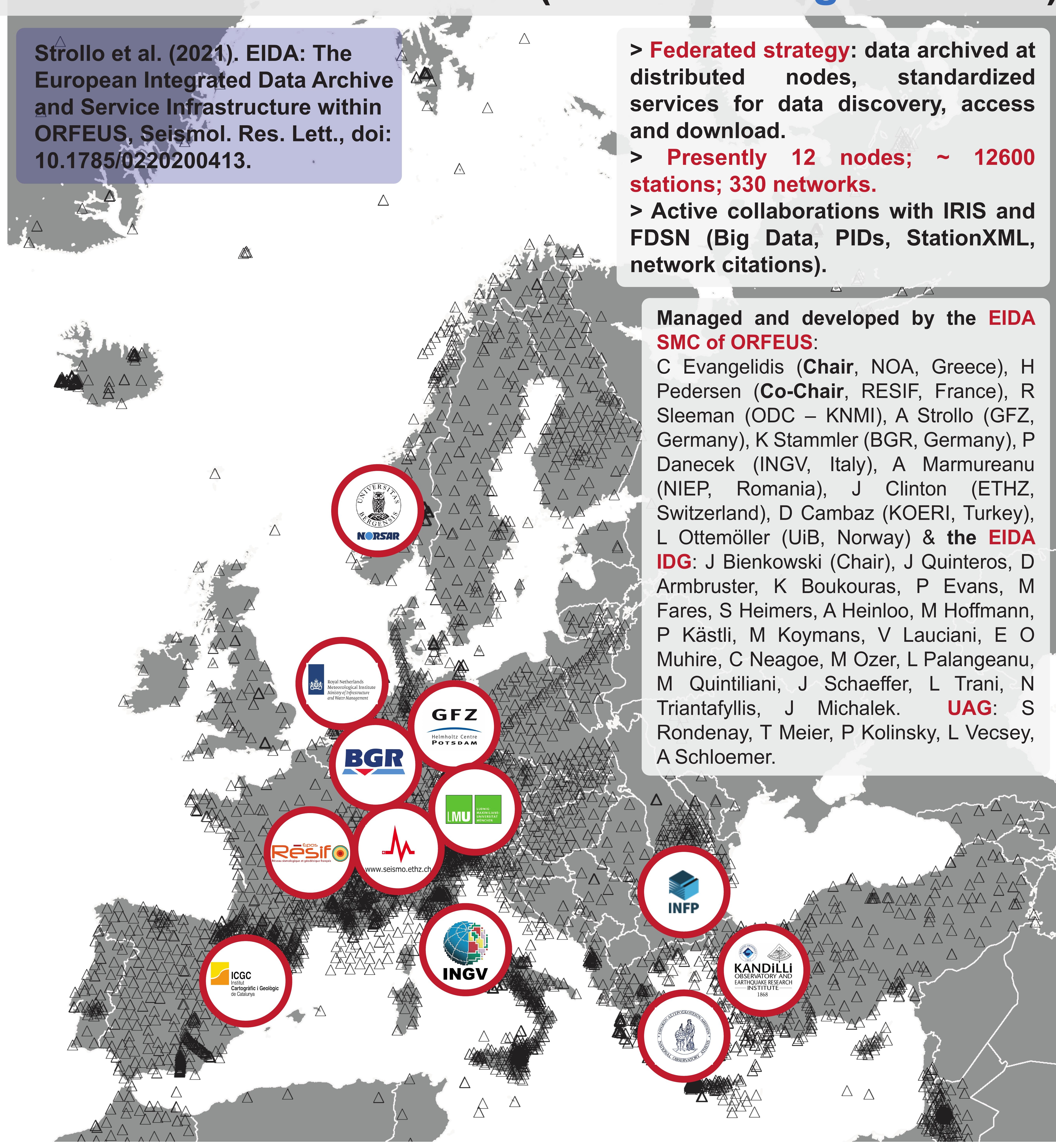

EIDA Web Interfaces

$>$ http://orfeus-eu.org/webdc3/

ORFEUS Data Center WebDC3 Web Interface

(2)

Allows for:

(EMSC, GFZ, KNMI, INGV, ETH, USGS): catalogues

archive; downloading raw waveform data (SEED format) and associated metadata (SEED and XML) for user-defined
time windows, including OT-based start and end times. COMING SOON: new Web Interface chiefly based on Web

$>$ http://orfeus-eu.org/stationbook/

$>$ Allows discovery and download of metadata of stations
contributing to EIDA.

(Meta)data quality/availability tools

> https://wwww.orfeus-eu.org/data/eida/quality/
Data metrics \& availability

Data metrics \& availability
Waveform plots

Waveform plots
Instrument responses

Documentation and user feedback

$>$ https://www.orfeus-eu.org/data/eida
$>$ httrs //lorfeus-en.readthedocs.io
$>$ https://github.com/EIDA/userfeedback
EIDA Web Services http://orfeus-eu.org/data/eida/webservices FDSN webservice fdsnws-dataselect
Provides waveform data in MSEED forma Provides waveform data in MSEED format FDSN webservice fdsnws-station
Provides station metadata in XML and text format.
http://www.orfeus-eu.org/ffdsnws/station//1query? IDA webservice eidaws-routing Provides routes to different EIDA data and services
http://www.orfeus-eu.orgleidaws/routing///query? EIDA webservice eidaws-wfcatalog

Provides metadatatand auality parameters of wf data
http://www.orfeus-eu.org/leidaws/wfcatalog/1/query? EIDA Federator

位 http://leida-fedederator. ethz.ch//dsnnws/station/1/query?

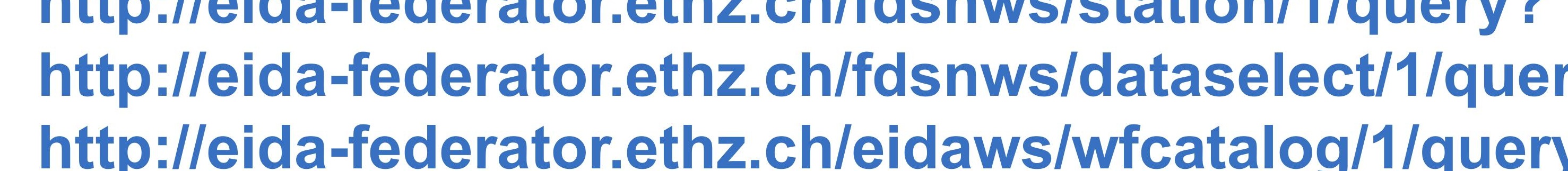
Advanced examples available at:
https://www.orfeus-eu.org/datataleida/webservices/
examples//workflow/

Other clients and tools

> Seismo-Live (Jupyter Notebooks)
ORFEUS Strong-Motion Databases

and Associated Services

(orfeus-eu.org/data/strong)

SERA

Rapid Raw Strong-Motion (RRSM) Engineering Strong-Motion (ESM) Products

$$
\text { Products }
$$

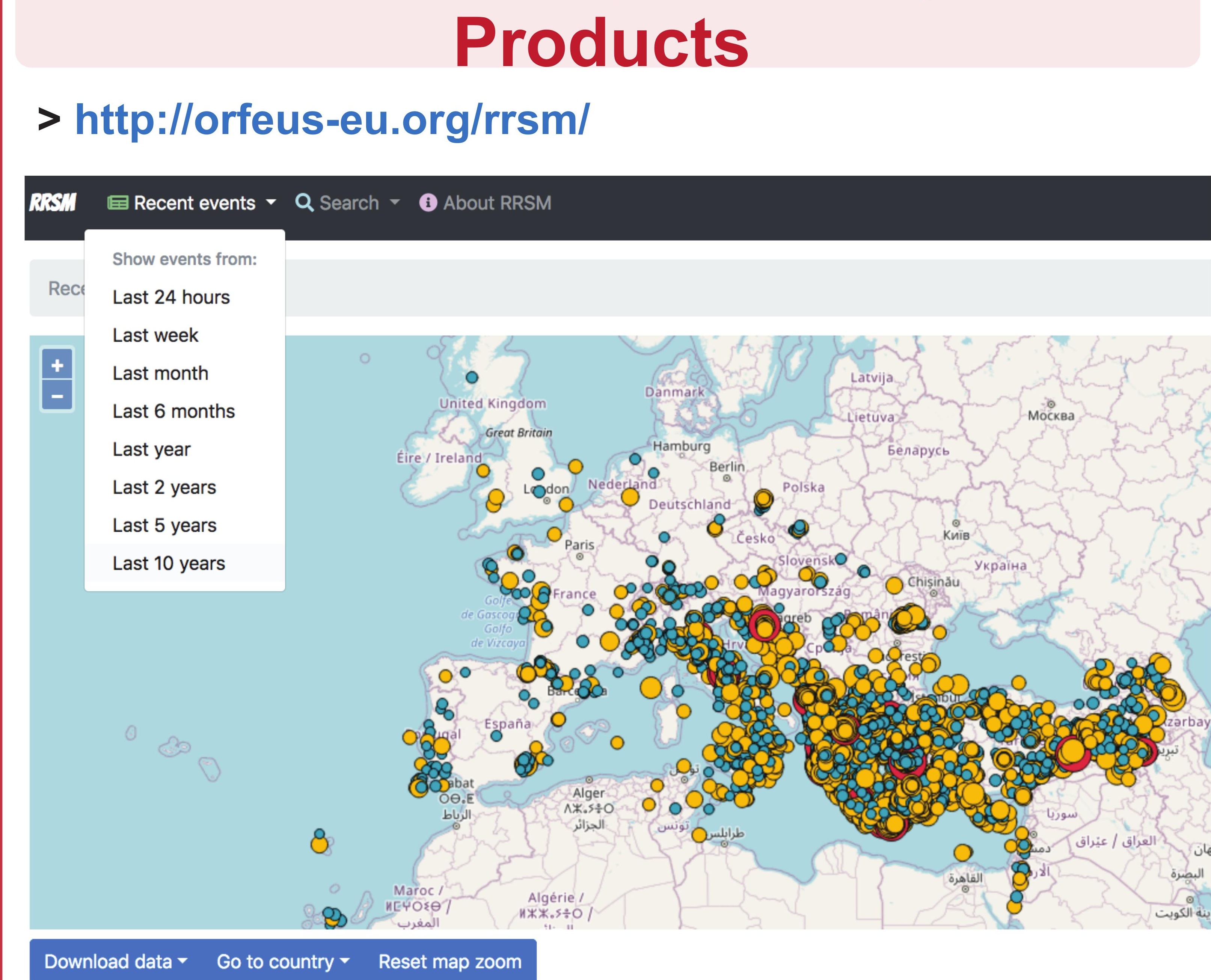
- Triggering by bMSC reports of any earthquake with
M gany scale) $>=3.5$ in the Euro-Med region.
- Collection of input data in near-real-time from EIDA - Automatic processing based on $\mathrm{SC} 3$ module
scwfparam and SC3 SM database extension -

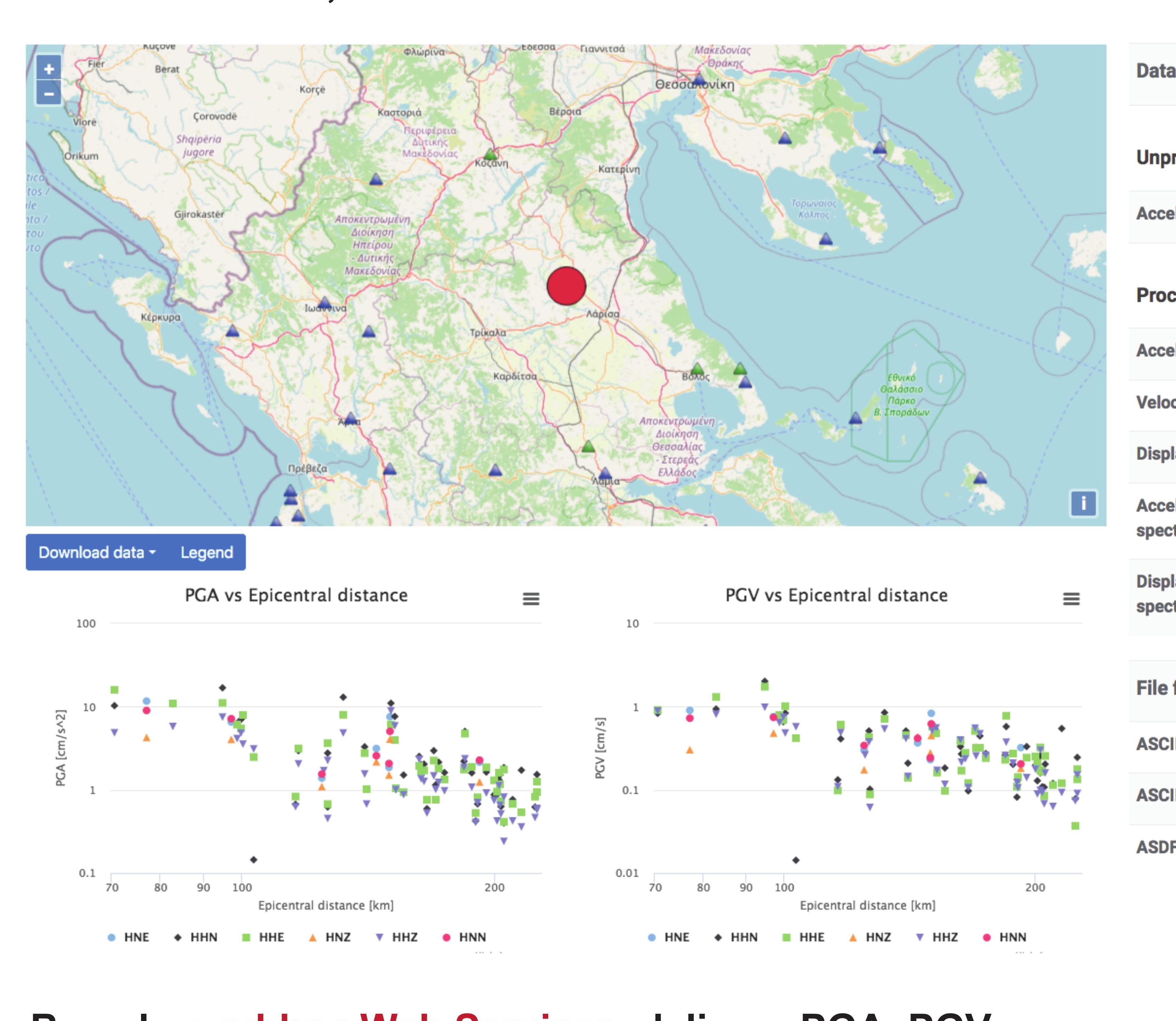

Based on ad-hoc Web Services, delivers PGA, PGV,
SA(T), SD(T), raw and processed waveforms in $S E$, format.

$>$ Web Services deliver input files to USGS-style ShakeMap v3.5, raw and processed waveforms, event
and peak-motion information in json and text formats.

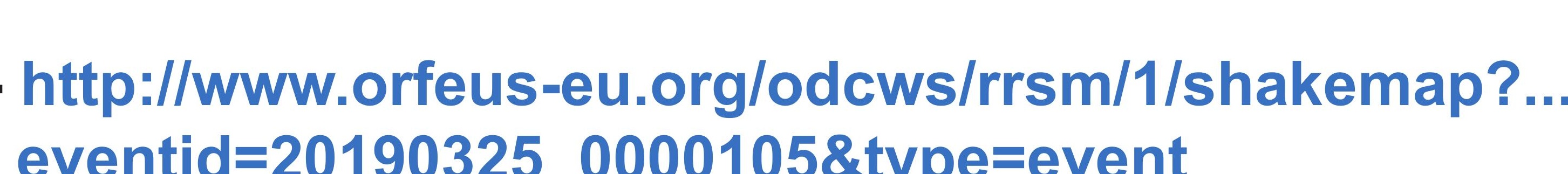
- http:///www.orfeus-eu.org/odcws/rrsm/1/shakemap?

COMING SOON: better identification of outliers, Jupyter
nootbooks for self processing, improved automated nootbooks for
processing.

http://orfeu Products

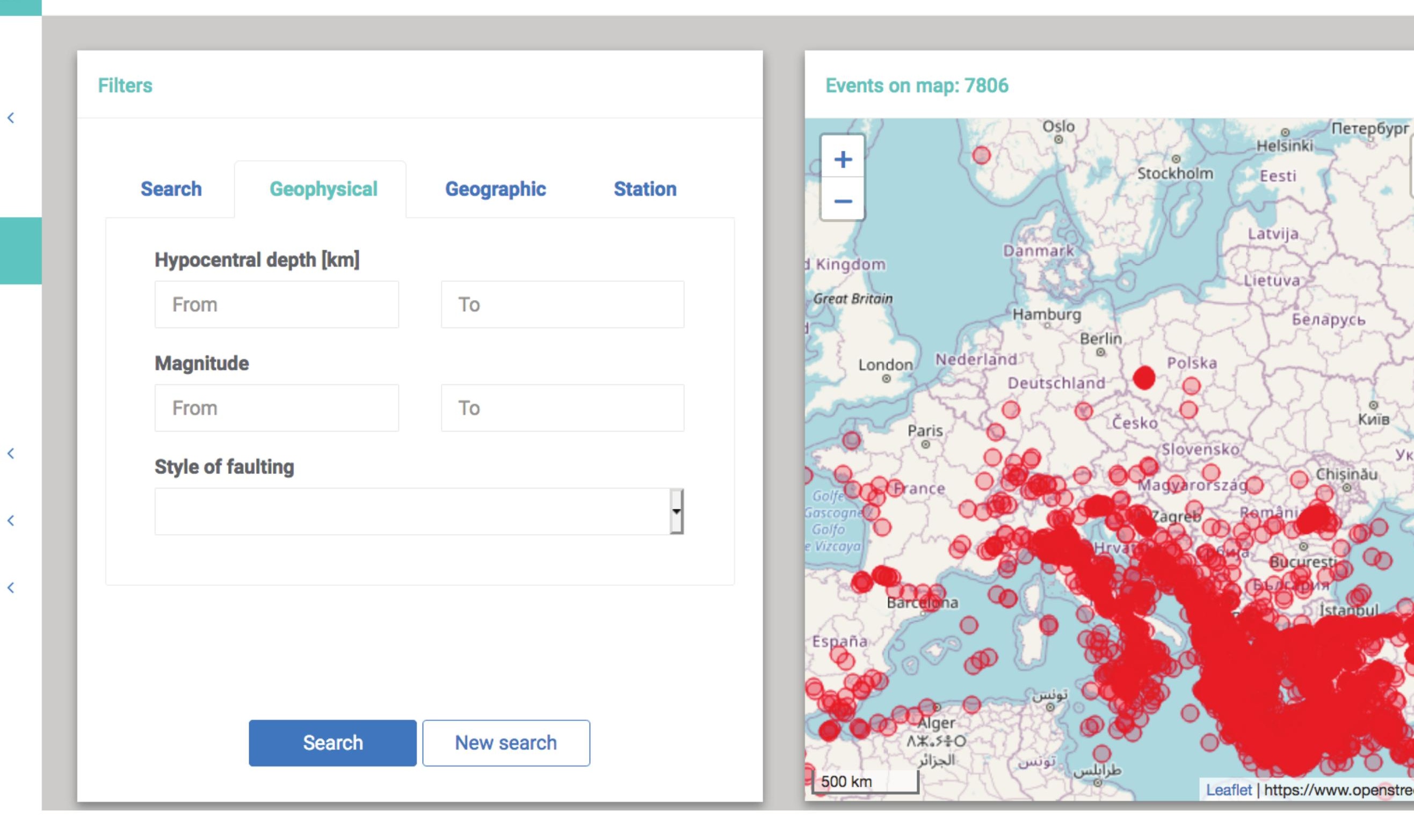

-Manual processing software based on Puglia et al.

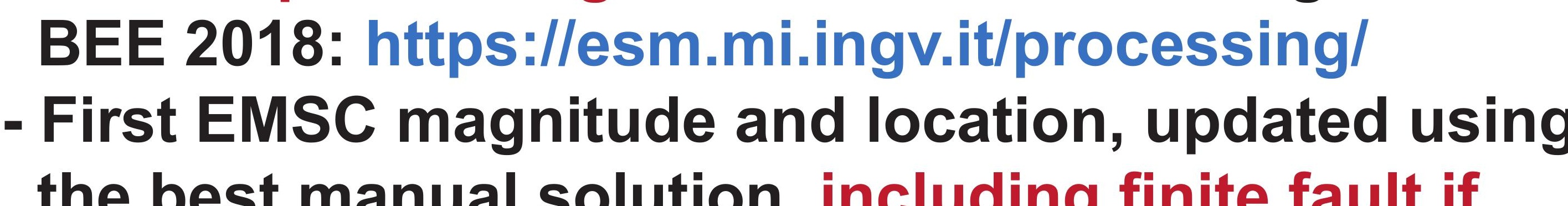

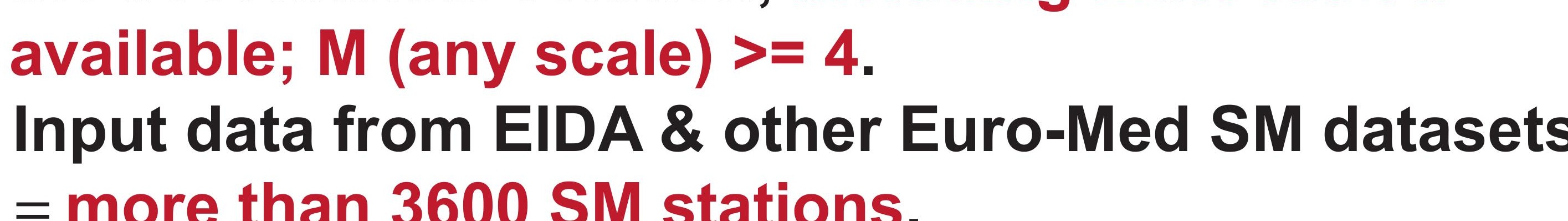

Emen

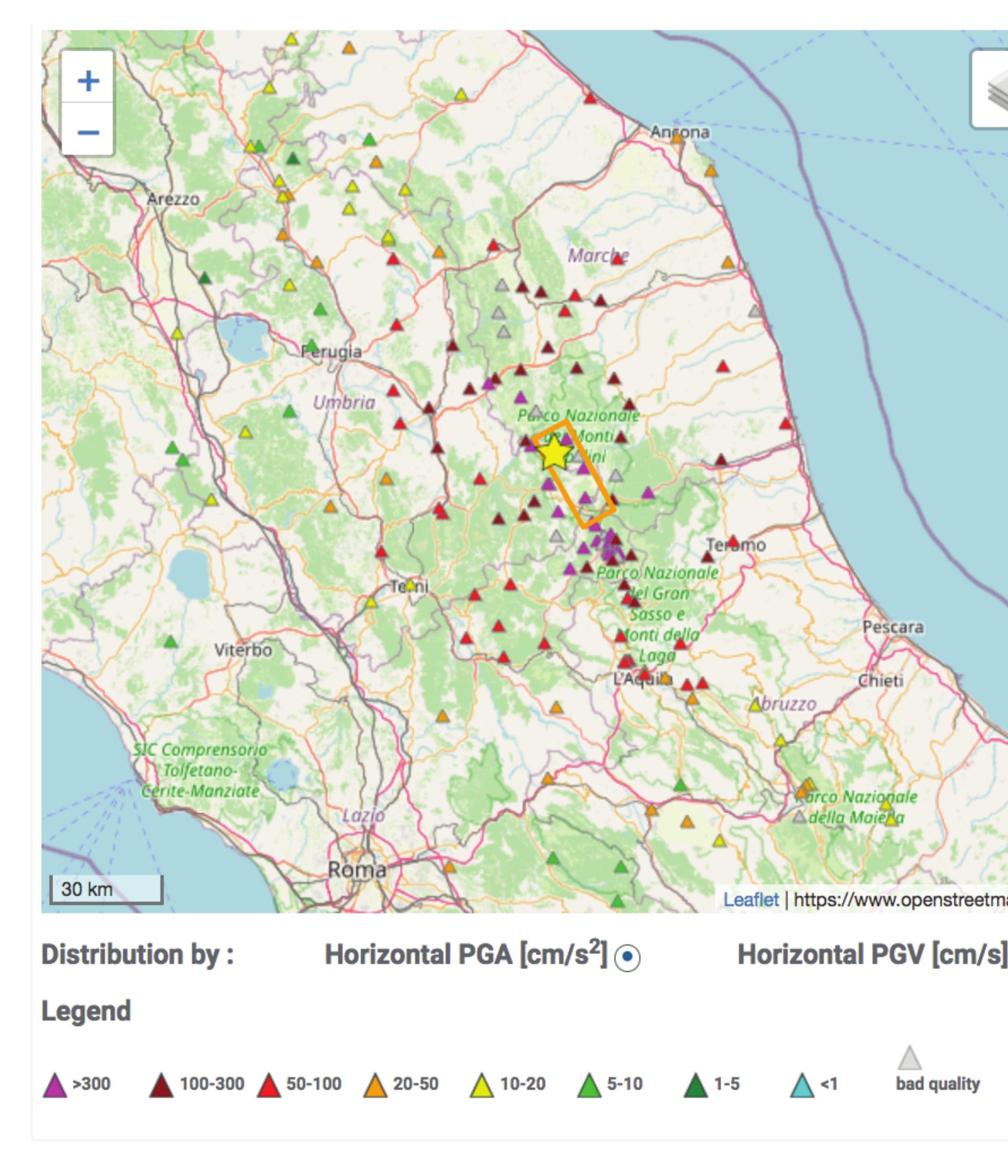

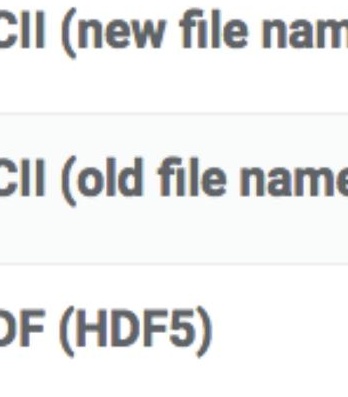

Delivers PGA, PGV, selected spectral ordinates, parameters, raw and and processed waveforms - also spectrum-compatible
(REXELLeb) - in engineering formats including ASCII and

Web Services deliver manually revised input files to
USGS-style ShakeMap (event, peak-motion and fault data)

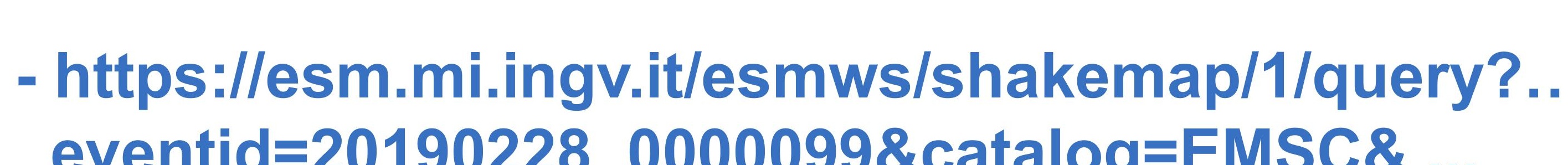
format=event - hittps://lesm.mi.ingv.ittesmws/shakemap/1/query?
eventid=20190228_00000998catalog=EMSC\&...

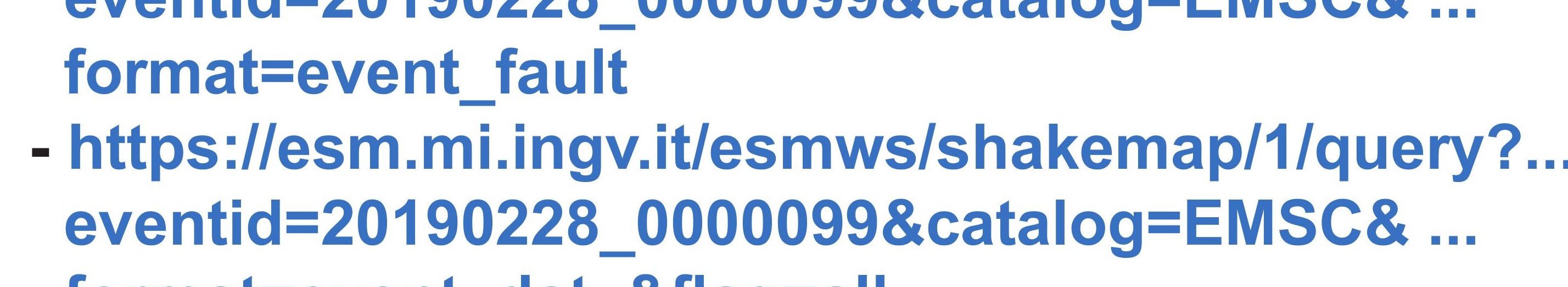
=event_dat \&flag=al

COMING SOON: additional fo
processed data and products.

Lanzano et al. (2021). Accessing European Strong Motion Data: An Update on ORFEUS Coordinated Services, Seismol. Managed and developed by the Strong-Motion SMC of ORFEUS:
G Lanzano (Chair, ESM \& INGV, Italy), LLuzi ESM \& INGV, Italy), RS

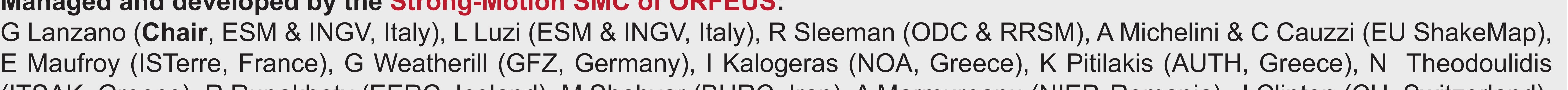

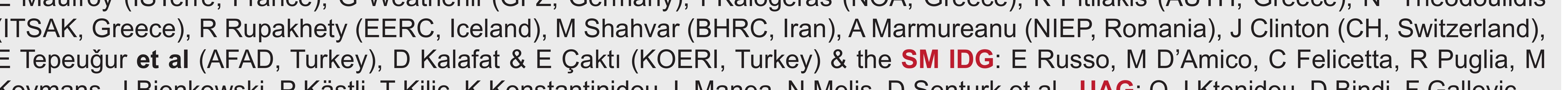

